\title{
Genetic Variation in Jasmonic Acid- and Spider Mite-Induced Plant Volatile Emission of Cucumber Accessions and Attraction of the Predator Phytoseiulus persimilis
}

\author{
Iris F. Kappers • Francel W. A. Verstappen • \\ Ludo L. P. Luckerhoff • Harro J. Bouwmeester • \\ Marcel Dicke
}

Received: 10 September 2009 / Accepted: 23 March 2010/Published online: 13 April 2010

(C) The Author(s) 2010. This article is published with open access at Springerlink.com

\begin{abstract}
Cucumber plants (Cucumis sativus L.) respond to spider-mite (Tetranychus urticae) damage with the release of specific volatiles that are exploited by predatory mites, the natural enemies of the spider mites, to locate their prey. The production of volatiles also can be induced by exposing plants to the plant hormone jasmonic acid. We analyzed volatile emissions from 15 cucumber accessions upon herbivory by spider mites and upon exposure to jasmonic acid using gas chromatography - mass spectrometry. Upon induction, cucumber plants emitted over 24 different compounds, and the blend of induced volatiles consisted predominantly of terpenoids. The total amount of volatiles was higher in plants treated with jasmonic acid than in those infested with spider mites, with (E)-4,8-dimethyl-1,3,7-nonatriene, $(E, E)-\alpha$-farnesene, and $(E)-\beta$-ocimene as the most abundant compounds in all accessions in both treatments. Significant variation among the accessions was found for the 24 major volatile compounds. The accessions differed strongly in total amount of volatiles emitted, and displayed
\end{abstract}

I. F. Kappers • L. L. P. Luckerhoff • M. Dicke

Laboratory of Entomology,

Wageningen University and Research Centre Wageningen,

Wageningen, The Netherlands

I. F. Kappers $(\varangle) \cdot$ F. W. A. Verstappen - L. L. P. Luckerhoff •

H. J. Bouwmeester

Plant Research International,

Wageningen University and Research Centre Wageningen,

Wageningen, The Netherlands

e-mail: i.f.kappers@wur.nl

F. W. A. Verstappen · H. J. Bouwmeester

Laboratory of Plant Physiology,

Wageningen University and Research Centre Wageningen,

Wageningen, The Netherlands very different odor profiles. Principal component analysis performed on the relative quantities of particular compounds within the blend revealed clusters of highly correlated volatiles, which is suggestive of common metabolic pathways. A number of cucumber accessions also were tested for their attractiveness to Phytoseiulus persimilis, a specialist predator of spider mites. Differences in the attraction of predatory mites by the various accessions correlated to differences in the individual chemical profiles of these accessions. The presence of genetic variation in induced plant volatile emission in cucumber shows that it is possible to breed for cucumber varieties that are more attractive to predatory mites and other biological control agents.

Key Words Cucumis sativus L. Tetranychus urticae. Phytoseiulus persimilis · Cucumber · Spider mite . Predatory mite $\cdot$ Herbivore-induced plant volatiles . Tritrophic interactions

\section{Introduction}

Cucumis sativus $\mathrm{L}$. is grown in nearly all temperate regions and is one of the ten most widely cultivated vegetable species, ranking fourth after tomato, onion, and cabbage (Tatlioglu 1993). Cucumber is indigenous to India, and its domestication started there approximately 3,000 years ago, followed by spreading into Western Asia and then southern Europe. In cucumber breeding programs, genotypes are selected for improved performance in specific environments (greenhouse, field, single, or multiple harvest), as well as for intended use (processing, fresh market), consumer preference (fruit shape and quality), pest and diseases 
resistance, abiotic stress tolerance, and high fruit yield. It has been observed that the genetic base of commercial cucumber germplasm is not very broad (Staub and Meglic 1993). Despite the agricultural and biological importance of cucurbits, knowledge of their genetics and genome currently is limited (Huang et al. 2009). Moreover, the historical reservoirs of genetic variation in cucumber, such as India (primary center), Burma, and Southern China (secondary center), are subject to genetic erosion (Tatlioglu 1993). So far, plant breeders have hardly selected for crop characteristics that influence the success of biological control (but see Van Lenteren and De Ponti 1990) even though it is obvious that for successful biological control it is important that biological control agents also can find the herbivores, at low densities (Dicke 1999).

Plants respond to herbivore feeding with the production of volatiles that natural enemies use as cues to locate the herbivores. This phenomenon has been observed in various tritrophic systems and is an important mechanism by which plants defend themselves against herbivorous insects (e.g., Dicke and Van Loon 2000; Arimura et al. 2005; Dudareva et al. 2006; D'Alessandro and Turlings 2006; Mumm and Hilker 2006; Hilker and Meiners 2010). Induced defenses allow plants to be cost-effective and also to diminish the risk that herbivores will adapt to plant defenses (Heil 2008; Steppuhn and Baldwin 2008). Plants exhibit variation in these traits, which comprises both intra-individual phenotypic plasticity and genetic polymorphisms among individuals and populations. The plasticity of inducible defense allows individual plants to adapt to changing environments (Agrawal 2001). Polymorphism in traits for resistance against herbivory may result from varying selection pressures among populations.

Herbivory Induced Plant Volatile (HIPV) blends vary considerably both in quantity and quality with plant species or plant varieties (Krips et al. 2001; Hoballah et al. 2002; Degen et al. 2004; Van den Boom et al. 2004; Bukovinszky et al. 2005; Lou et al. 2006). This may result in differences in the degree of attraction of natural enemies of the herbivores (Krips et al. 2001; Hoballah et al. 2002; Bukovinszky et al. 2005; Lou et al. 2006). Knowledge of which of the induced volatiles have ecological significance may aid eventually the development of methods to enhance the attractiveness of crop varieties to beneficial arthropods. Typical plant volatiles that are induced by herbivory are green leaf volatiles: C6-alcohols, -aldehydes and -acetates; phenylpropanoids such as methyl salicylate; and various monoterpenes and sesquiterpenes, as well as two homoterpenes: $(E)$-4,8-dimethyl-1,3,7-nonatriene (DMNT) and $(E, E)$ 4,8,12-trimethyl-1,3,7,11-tridecatetraene (TMTT) (Arimura et al. 2005; Dudareva et al. 2006). Green leaf volatiles are fatty acid derivatives that result from the lipoxygenase pathway (D'Auria et al. 2007). Terpenoids are synthesized either via the cytosolic mevalonate (MVA) pathway or via the methylerythritol 4-phosphate (MEP) pathway in the plastids (Aharoni et al. 2005; Rodríguez-Concepción 2006).

The objectives of this study were to explore the variation among cucumber accessions with respect to herbivoryinduced volatile emission and to determine to what extent differences in volatile profiles affect the attraction of predatory mites. We compared the volatile emission of various cucumber accessions in response to spider-mite (Tetranychus urticae) infestation and jasmonic acid treatment, as well as the attractiveness of a number of these accessions to the predatory mite Phytoseiulus persimilis.

To take differences in direct defense into account, e.g., due to differences in cucurbitacin $\mathrm{C}$ content (BalkemaBoomstra et al. 2003), jasmonic acid was used to standardize the level of induction, as the production of many induced volatiles is mediated by the jasmonic acid signalling (Dicke et al. 1999; Gols et al. 1999; Degenhardt and Lincoln 2006; Ozawa et al. 2008). Previous work demonstrated that spider-mite infestation and jasmonic acid both induce similar components in the volatile blend of cucumber, albeit in different amounts and at a different time scale (Bouwmeester et al. 1999; Mercke et al. 2004).

\section{Methods and Materials}

Plants, Herbivores and Predators Cucumber (Cucumis sativus) seeds were obtained from the Centre for Genetic Resources, the Netherlands (CGN), which is part of Wageningen University and Research Centre. As there is little to no information about genetic variation in relation to induced volatiles in cucumber, seven accessions were chosen as representative of various places of origin. In addition, eight cucumber F1-hybrids from commercial breeders were chosen. Seeds were sown and grown at $22-23^{\circ} \mathrm{C}, 60-70 \%$ relative humidity, and $16 \mathrm{hr}$ of light per day in a greenhouse at Wageningen University, The Netherlands. SON-T lamps were used to supply extra light when the natural light intensity decreased below $250 \mu \mathrm{mol} \mathrm{m} \mathrm{m}^{-2} \mathrm{sec}^{-1}$. Plants used for experiments were 3-4-wk-old and had four or five fully expanded leaves.

Two-spotted spider mites, Tetranychus urticae Koch, were reared on lima bean plants (Phaseolus lunatus) in a greenhouse at $24 \pm 4^{\circ} \mathrm{C}, 60 \pm 20 \%$ relative humidity and a 16:8 hr, L:D photoperiod. For spider mite-infestation, approximately 50 adult female spider mites were evenly distributed on the adaxial side of fully expanded leaves with a fine brush.

Predatory mites, Phytoseiulus persimilis Athias-Henriot, were reared on spider mite-infested lima bean leaves to exclude that predator behavior could be influenced by exposure to cues emitted from one specific cucumber accession above others (Dicke et al. 1990b; Takabayashi 
and Dicke 1992). Predators were reared in a growth chamber at $23 \pm 1{ }^{\circ} \mathrm{C}, 60 \pm 10 \% \mathrm{RH}$ and continuous light. Before experiments, females were starved individually in $1.5 \mathrm{ml}$ microcentrifuge tubes for $3 \pm 0.5 \mathrm{hr}$ at $23 \pm 1^{\circ} \mathrm{C}$.

Application of Jasmonic Acid Plants were sprayed with a $0.5 \mathrm{mM}( \pm)-J A$ solution (Sigma-Aldrich, St. Louis, MO, USA) with $0.01 \%$ Tween-20 using an aerosol spray bottle until completely wet (ca $5 \mathrm{ml}$ per plant). Mock treated plants were sprayed with water containing $0.01 \%$ Tween20. JA-sprayed plants were separated from control and spider-mite infested plants in a different greenhouse compartment but under the same environmental conditions.

Collection and Analysis of Induced Cucumber Volatiles To allow valid comparison of the composition and quantities of the volatiles, headspace samples were collected from all accessions at the same time during the photoperiod. As there were several experiments in different periods of the year, the variety 'Hybrid C' was used as a reference in all experiments. Individual plants were enclosed in glass cuvettes $(2.5$ 1) with a viton-lined lid equipped with an inlet and an outlet and placed in a climate room at $21 \pm 1^{\circ} \mathrm{C}$ and a light intensity of $120 \mu \mathrm{mol} \mathrm{m} \mathrm{msec}^{-1}$. A vacuum pump was used to draw air through the glass cuvette at approximately $100 \mathrm{ml} \mathrm{min}^{-1}$ with the incoming air being purified through a cartridge containing $200 \mathrm{mg}$ of Tenax TA (20/35-mesh, Alltech). At the outlet, the volatiles emitted by the plants were trapped on a similar cartridge. For quantification of the volatiles released, carvone and benzyl acetate in hexane were added as internal standards in a Tshaped glass liner placed between the cuvette and the Tenax outlet. For spider-mite infested plants, $600 \mathrm{ng}$ of each compound were added to the cuvette, whereas in case of JA-treated plants, $6 \mathrm{ng}$ were added. Volatiles were sampled for $3 \mathrm{hr}$. Volatiles from at most 11 accessions were collected simultaneously, and five replicate samples were collected for each accession over time (Hybrid C 12 times). To check for background volatiles, released by e.g., materials used, volatiles from empty jars were trapped as well. The amounts of the 24 dominating compounds were quantified in area units under the curve, and were corrected using the response factors of each compound towards the internal standard closest in retention time. For compounds for which we did not have a standard, we estimated the amounts emitted based on the average response factor of compounds between RI 850 and 1,000 (for compounds $\mathrm{d}$, e, and $\mathrm{f}$ ); on the response factor of (E)- $\beta$-ocimene (for compound $\mathrm{k}$ ), or on the average response factor of homo- and sesquiterpenes $\mathrm{q}, \mathrm{t}, \mathrm{w}$, and $\mathrm{x}$ (for compounds $\mathrm{r}, \mathrm{u}$, and $\mathrm{v}$ ).

Gas Chromatography-Mass Spectrometry Headspace samples of cucumber plants were analyzed on a Hewlett-
Packard GC-MS or on a Trace GC Ultra ${ }^{\mathrm{TM}}$ (Thermo Electron Corporation, Austin,TX, USA) equipped with a Trace DSQ quadrupole mass spectrometer (Thermo Electron Corporation, Austin,TX, USA). For this, Tenax cartridges either were eluted using $3 \times 1 \mathrm{ml}$ of re-distilled pentane : diethyl ether $(4: 1)$ or released from Tenax traps using a thermal desorption cold trap setup (TDS; UNITYTM, Markes international LTD, UK). After elution, samples were concentrated to about $30 \mu \mathrm{l}$, of which $2 \mu \mathrm{l}$ were analyzed by GC-MS using a gas chromatograph (5,890 series II, Hewlett-Packard) equipped with a $30-\mathrm{m} \times$ $0.25-\mathrm{mm}$ i.d., $0.25-\mu \mathrm{m}$ film thickness column (5MS, Hewlett-Packard) and a mass-selective detector (model 5972A, Hewlett-Packard). The GC was programmed at an initial temperature of $45^{\circ} \mathrm{C}$ for $1 \mathrm{~min}$, with a ramp of $10^{\circ} \mathrm{C} \mathrm{m^{-1 }}$ to $220^{\circ} \mathrm{C}$, and final time of $5 \mathrm{~min}$. The injection port (splitless mode), interface, and MS source temperatures were $250^{\circ} \mathrm{C}, 290^{\circ} \mathrm{C}$, and $180^{\circ} \mathrm{C}$, respectively, and the $\mathrm{He}$ inlet pressure was controlled with an electronic pressure control to achieve a constant column flow of $1.0 \mathrm{ml} \mathrm{min}$. The ionization potential was set at $70 \mathrm{eV}$, and scanning was performed from 30 to $250 \mathrm{amu}$.

Tenax cartridges analyzed on the Trace GC were first dry-purged with helium at $100 \mathrm{ml} \mathrm{min}{ }^{-1}$ for $10 \mathrm{~min}$ at ambient temperature to remove any water. Volatiles were released from Tenax traps using a thermal desorption cold trap setup by heating at $250^{\circ} \mathrm{C}$ for $3 \mathrm{~min}$, with a He flow of $30 \mathrm{ml} / \mathrm{min}$. Desorbed volatiles then were transferred to an electronically-cooled focusing trap at $-10^{\circ} \mathrm{C}$ within the TDS. Volatiles were injected in splitless mode into the analytical column (Restek, RTX 5MS, $30 \mathrm{~m} 0.25 \mathrm{~mm}$ i.d., $1.0 \mu \mathrm{m} d f$ ) by heating the cold trap to $300^{\circ} \mathrm{C}$. The $\mathrm{GC}$ was held at the initial temperature of $40^{\circ} \mathrm{C}$ for $3.5 \mathrm{~min}$ followed by a linear thermal gradient of $10^{\circ} \mathrm{C} / \mathrm{min}$ to $280^{\circ} \mathrm{C}$, and held for $2.5 \mathrm{~min}$ with a He flow of approximately $1 \mathrm{ml} / \mathrm{min}$. The column was coupled directly to the ion source of the DSQ quadrupole mass spectrometer, which was operated in the $70 \mathrm{eV}$ EI ionization mode and scanned from mass 45 to $400 \mathrm{amu}$. An auto sampler was used for the automatic desorption of the Tenax traps (UltrA $^{\mathrm{TM}}$, Markes international Ltd, UK). The TC-20 Multi-tube conditioning unit (Markes International Ltd, UK) was used for cleaning the cartridges in between the measurements by heating them to $310^{\circ} \mathrm{C}$ for $40 \mathrm{~min}$ under a He flow. Compounds were identified by comparing the mass spectra with the Wiley and NIST mass spectral libraries and by comparing retention indices with Adams (1995). Headspace samples of plants exposed to spidermite infestation in a time-series experiment were analyzed on the HP-GC-MS, whereas for the experiment where the headspace from JA-treated plants were compared to the headspace of spider-mite infestations was analyzed by thermodesorption GC-MS. 
Olfactometer Set-up and Predatory Mite Bioassay To compare the responses of predatory mites to the induced volatiles of a selection of accessions we used a closed Ytube olfactometer as previously described (Takabayashi and Dicke 1992; Bukovinszky et al. 2005). Odor sources consisted of a single plant with 4-5 leaves that were infested with 50 spider mites $1 \mathrm{wk}$ prior to the experiment or induced with JA $24 \mathrm{hr}$ prior to the experiment. Experiments compared plants of different accessions that both were infested with spider mites or that were both induced with JA. For each accession, induced plants also were tested against non-induced plants. Individual female predators were released on an iron wire in the basal tube, and their behavior was observed for a maximum of $5 \mathrm{~min}$. The connections of the odor sources to the arms of the olfactometer were interchanged after testing a series of five predators. A choice was recorded when the finish line, halfway up one of the olfactometer arms, was reached within this period. Otherwise it was recorded as no-choice. Each predator was used only once. Per experimental day, 20 predators were tested for each odor combination, and each experiment was repeated on 3-5 different days.

Statistical Analysis Not all volatiles were detected in every replicate of every accession. To be able to determine ratios among accessions and allow log-transformation of data, we added 1,000 area units to all data points, representing the lowest recorded non-zero value. A number of volatiles were not included in the data analysis because they occurred in one or two accessions only, with an abundance of less than $0.1 \%$ of the total volatile production.

Peak areas of all compounds were corrected for fresh weight of the leaves. Per compound, the Student's t-test was used to determine whether the compound was induced significantly by herbivory. Experiments were conducted over a period of $2 \mathrm{yr}$. To correct for the inevitable variation in the absolute amounts of individual volatiles, emissions are given as least-squares means as calculated by two-factor ANOVA, with experimental period as the second factor.

Standard Pearson correlation coefficients were determined among individual accessions for each volatile and a Student's t-test was used to determine the significance of these correlations. Cluster and correlation analysis also were performed using Genemaths (Applied Maths, SintMartens-Latem, Belgium). Principal component analysis (PCA) involves a mathematical procedure that transforms a number of possibly correlated variables into a smaller number of uncorrelated variables called principal components. PCA gives complementary information to ranking lists based on correlation coefficients to specific volatiles. The significance level for correlations was set at $P<0.05$. To comply with ANOVA assumptions, all volatile emission data were log-transformed and normalized (mean of complete data-set set to zero) by dividing by the average volatile emission rate calculated from all experiments.

The choices of predatory mites between odor sources in the Y-tube olfatometer were analyzed with two-sided binominal tests to determine whether the distribution of the predators' choice was significantly different from 50:50. Predators that did not make a choice were excluded from the statistical analysis.

\section{Results}

The headspace of cucumber plants induced by spider-mite feeding or treatment with JA consisted of a maximum 24 volatile compounds that collectively represented more than $98 \%$ of the total emission of cucumber leaf volatiles (Table 1). Most of these compounds were not detected in the headspace of non-induced plants, except for nonanal, decanal, limonene, (E)-2-hexenal, and (Z)-3-hexenyl acetate, which were present also in trace amounts in noninduced plants. Methyl jasmonate and jasmone sometimes were detected in the headspace of JA-treated plants, but not in the headspace of mite-damaged plants. Because these two compounds likely are a direct consequence of the JA treatment, they were not included in the statistical analyses.

No visual damage was observed after JA-treatment, whereas spider-mite damage led to a decrease of about 8 $14 \%$ of the chlorophyll content during a 7-d-period of feeding (data not shown). Feeding damage was sufficient to cause an increase in the total amount of volatiles from day 1 onwards (Fig. 1). Progressing infestation of the mites increased volatile release with time (Fig. 1). JAapplication resulted in the release of volatiles from treated leaves within $2 \mathrm{hr}$ and was maximal after 2-3 d (Table 2). The total emission of volatiles varied strongly among the various accessions, ranging from about $80 \mathrm{ng}$ per plant to over $6 \mu \mathrm{g}$ per plant (Table 2). After $3 \mathrm{~d}$, the volatile emission rate diminished (data not shown).

Mite feeding and JA application both increased the emission of many compounds. By far, the most abundant compounds in plants induced either by $T$. urticae infestation or by JA treatment were DMNT, $(E)-\beta$-ocimene, $(E, E)-\alpha$ farnesene, and (Z)-3-hexenyl acetate (Fig. 2). However, there is a large range of variation among accessions for all compounds (Table 1, Fig. 2). The majority of induced compounds were terpenoids: about $75 \%$ of the total volatile blend, consisting of six monoterpenoids [ $\alpha$-phellandrene, thujene, $(Z)$ - $\beta$-ocimene, $(E)$ - $\beta$-ocimene, limonene, linalool], two homoterpenes [DMNT, TMTT], and five sesquiterpenoids $[(E)-\beta$-caryophyllene, $(E, E)$ - $\alpha$-farnesene, and three unknown sesquiterpenoids]. The remaining compounds were an aldehyde, two alcohols, three acetate 
Table 1 Variation in volatile compounds emitted by cucumber plants of different origin that were infested with spider mites during 7 days or were treated with jasmonic acid (JA) 2 days prior to headspace collection

\begin{tabular}{|c|c|c|c|c|c|c|c|c|}
\hline \multirow[t]{3}{*}{ Compound $^{\mathrm{a}}$} & \multirow[t]{3}{*}{ Biochemical class } & \multirow{3}{*}{\multicolumn{2}{|c|}{ RI (RI STD) }} & \multicolumn{5}{|c|}{ Relative Quantities ${ }^{2}$ of Compounds in Volatile Blend } \\
\hline & & & & \multirow{2}{*}{$\begin{array}{l}\text { Non-treated } \\
\text { Mean } \pm \text { SE }\end{array}$} & \multicolumn{2}{|c|}{ JA treated (2 days) } & \multicolumn{2}{|c|}{ Spider mite infested ( 7 days) } \\
\hline & & & & & Mean \pm SE & Range & Mean \pm SE & Range \\
\hline a (E)-2-Hexenal & lipid derivative & $851(849)$ & STD & $43.0 \pm 7.9$ & $0.45 \pm 0.2$ & 0.8 & $0.41 \pm 0.2$ & 0.7 \\
\hline b (Z)-3-Hexen-1-ol & lipid derivative & $857(857)$ & STD & $3.5 \pm 1.6$ & $0.74 \pm 0.5$ & 3.4 & $0.40 \pm 0.8$ & 4.3 \\
\hline c 1-Hexanol & lipid derivative & $868(867)$ & STD & $2.1 \pm 0.9$ & $0.81 \pm 0.6$ & 3.0 & $0.91 \pm 0.8$ & 2.8 \\
\hline d Oxime 1 & $\mathrm{~N}$-aromatics & 925 & $\mathrm{Rt} / \mathrm{MS}$ & - & $0.57 \pm 0.2$ & 1.0 & $0.50 \pm 0.2$ & 0.7 \\
\hline e 3-Me-butanal-O-Me-oxime & $\mathrm{N}$-aromatics & 968 & $\mathrm{Rt} / \mathrm{MS}$ & $5.8 \pm 1.7$ & $4.22 \pm 1.6$ & 9.4 & $0.13 \pm 0.1$ & 0.1 \\
\hline f Nitrogen-containing compound & N-aromatics & 988 & $\mathrm{Rt} / \mathrm{MS}$ & $3.6 \pm 2.7$ & $2.05 \pm 0.9$ & 4.8 & $0.64 \pm 0.3$ & 0.9 \\
\hline g (Z)-3-Hexen-1-yl butyrate & lipid derivative & $1,159(1,161)$ & STD & - & $0.31 \pm 0.2$ & 0.9 & $0.41 \pm 0.3$ & 0.9 \\
\hline h (Z)-3-Hexen-1-yl acetate & lipid derivative & $1,013(1,015)$ & STD & $36.5 \pm 1.9$ & $8.27 \pm 3.4$ & 20.3 & $46.56 \pm 5.2$ & 19.0 \\
\hline i $\quad \alpha$-Phellandrene & monoterpenoid & $999(1,003)$ & STD & - & $1.60 \pm 0.5$ & 2.6 & $1.01 \pm 0.2$ & 0.8 \\
\hline j Thujene & monoterpenoid & $928(931)$ & STD & - & $0.54 \pm 0.2$ & 0.8 & $0.39 \pm 0.2$ & 0.8 \\
\hline $\mathrm{k} \quad(Z)$ - $\beta$-Ocimene & monoterpenoid & $1,037(1,040)$ & $\mathrm{Rt} / \mathrm{MS}$ & - & $0.71 \pm 0.2$ & 1.1 & $0.69 \pm 0.2$ & 0.9 \\
\hline $1 \quad(E)$ - $\beta$-Ocimene & monoterpenoid & $1,046(1,050)$ & STD & $2.6 \pm 0.9$ & $26.78 \pm 6.9$ & 42.3 & $7.11 \pm 2.3$ & 9.2 \\
\hline m Limonene & monoterpenoid & $1,032(1,031)$ & STD & - & $2.05 \pm 0.7$ & 4.2 & $1.04 \pm 0.4$ & 1.7 \\
\hline n Linalool & monoterpenoid & $1,096(1,098)$ & STD & - & $0.15 \pm 0.1$ & 0.6 & $0.23 \pm 0.2$ & 0.6 \\
\hline o Nonanal & & $1,097(1,098)$ & $\mathrm{Rt} / \mathrm{MS}$ & $2.9 \pm 0.2$ & $3.02 \pm 1.2$ & 7.0 & $2.79 \pm 1.0$ & 4.3 \\
\hline p Decanal & & $1,201(1,204)$ & $\mathrm{RT} / \mathrm{MS}$ & - & $3.17 \pm 1.1$ & 6.4 & $3.14 \pm 1.5$ & 5.9 \\
\hline q DMNT & homoterpenoid & 1,118 & STD & - & $16.28 \pm 8.5$ & 55.5 & $12.74 \pm 4.7$ & 21.9 \\
\hline r Unknown sesquiterpenoid & terpenoid & 1,121 & MS & - & $3.33 \pm 1.4$ & 8.0 & $1.79 \pm 1.6$ & 6.0 \\
\hline s Methyl salicylate & phenylpropanoid & $1,197(1,194)$ & STD & - & $0.73 \pm 0.6$ & 3.2 & $1.07 \pm 0.9$ & 2.3 \\
\hline $\mathrm{t} \quad(E)$ - $\beta$-Caryophyllene & sesquiterpenoid & $1,434(1,430)$ & STD & - & $2.22 \pm 1.4$ & 6.5 & $2.01 \pm 1.8$ & 6.8 \\
\hline u Unknown sesquiterpenoid & terpenoid & 1,460 & MS & - & $0.17 \pm 0.2$ & 0.8 & $0.27 \pm 0.2$ & 0.8 \\
\hline v Unknown sesquiterpenoid & terpenoid & 1,487 & MS & - & $1.03 \pm 1.4$ & 8.6 & $0.71 \pm 0.9$ & 3.6 \\
\hline $\mathrm{w}(E, E)-\alpha$-Farnesene & sesquiterpenoid & $1,534(1,534)$ & STD & - & $13.05 \pm 3.1$ & 18.2 & $13.30 \pm 3.8$ & 12.6 \\
\hline $\mathrm{x} \quad(E, E)$-TMTT & homoterpenoid & $1,554(1,555)$ & STD & - & $6.31 \pm 1.9$ & 10.9 & $3.3 \pm 0.8$ & 3.1 \\
\hline
\end{tabular}

${ }^{\text {a }}$ Identification of compounds is based on comparison with authentic (STD) or comparison with (KOVATS), retention index (RI) or on with mass spectra of various data bases (MS)

${ }^{\mathrm{b}}$ Quantities are given as proportion of the total blend \pm SE. The range of variation is an indication for genetic variation

esters, one nitrogen-containing aromatic compound, and two oximes. Most of these were released into the headspace within hours after the application of JA or within $1 \mathrm{~d}$ after spider-mite feeding started.

Experiments were performed during a 2-yr-period, and thus we have to deal with large absolute differences in volatile release. We, therefore, first analyzed volatile release of accessions for the relative contributions of individual compounds and found that these were rather constant over different experiments. Thus, the relative amount of e.g., (E)- $\beta$-ocimene varied between $35 \%$ and $40 \%$ in Hybrid T, $15-25 \%$ in CGN20890 and $9-16 \%$ in Hybrid C, and for DMNT, 25-32\%, 4-8\%, and 28-33\%, respectively. Furthermore, $(E)-\beta$-caryophyllene never was detected in headspace samples of Hybrid C and CGN20890, but it was detected in all samples of Hybrid $\mathrm{T}(1.5-5 \%)$. We, therefore, decided to use the data on the relative amounts from the different experiments within one multivariate analysis.

PCA is used in statistics to extract the main relationships in data of high dimensionality. The first axis of the PCA accounted for $42 \%$ of the total variation recorded in JAinduced plants. It was positively correlated with the quantity of all compounds that was included as a factor in the analyses and hence separated the accessions according to the total volatile emission. Therefore, we focused rather on the proportions of the compounds in the blend, as this may lead to a better distinction between different accessions. The second axis of the PCA accounted for $17 \%$ of the total variation recorded in JA-induced plants (Fig. 3). This component was correlated positively to the proportion of DMNT in the induced blend and roughly separated the European hybrids from the Asian and African landraces (Fig. 3). Indeed, European hybrids ranged from $11 \%$ to 
Fig. 1 Total amount of volatile compounds, i.e. the sum of 24 volatile compounds, Mean \pm SE emitted by 3 -wk-old Cucumis sativus plants of seven different accessions in response to spider-mite feeding during $14 \mathrm{~d}$. From left to right: accessions Hybrid T, CGN23412, Dasher, Korinda, Hybrid C, Vetabit and CGN19656. Headspaces were sampled on day $1,3,4,7,10$ and 14 after infestation

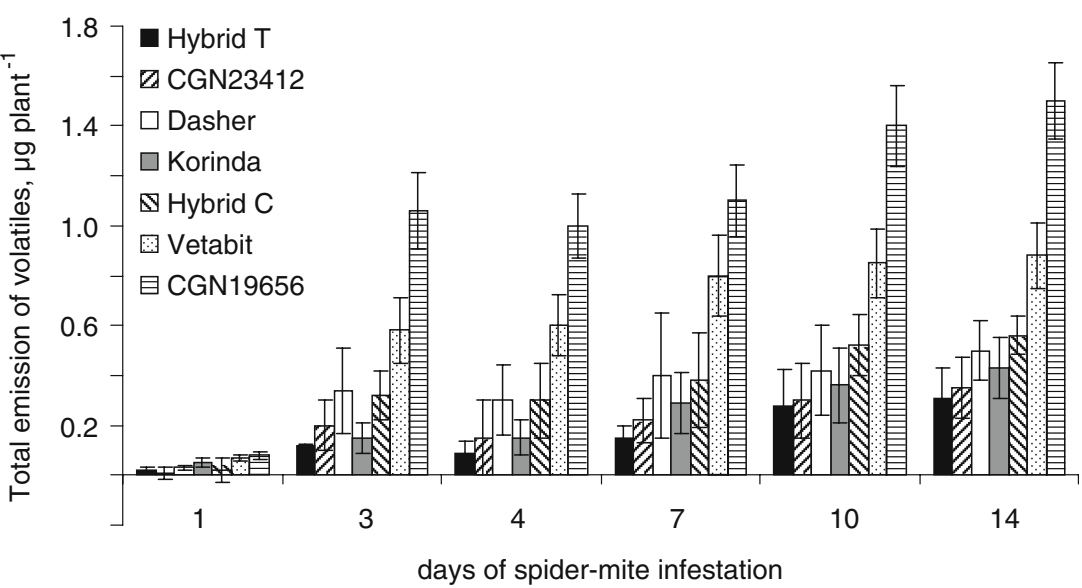

$56 \%$ DMNT in the volatile blend, whereas the accessions from Asia and Africa emitted only $15 \%$ to less than $1 \%$ of DMNT. The high proportion of DMNT in the European hybrids is correlated to a relatively low proportion of $(E)-\beta$ ocimene and $(E, E)$ - $\alpha$-farnesene in the volatile blends (Figs. 2, 3, Table 1).

A volatile-volatile matrix based on Pearsons correlation shows clusters of compounds whose proportions in the blend were correlated (positively): $(E)-\beta$-ocimene, $(E, E)-\alpha$-farnesene, and an unknown sesquiterpenoid one (mutual Pearson correlations of $>0.93$ ) cluster strongly together (Fig. 4). A second cluster was formed by limonene, thujene, and $\alpha$ phellandrene (mutual Pearson correlations $>0.80$ ) (Fig. 4). These three volatiles also clustered in the loading plot of the PCA (Fig. 3).
Responses of Predatory Mites We tested the preferences of the predatory mite Phytoseiulus persimilis for the volatile blends of a selection of accessions of spider-mite infested and JA-treated plants in a Y-tube olfactometer. Two hybrids were selected that had either a low (hybrid T) or a high volatile emission rate (hybrid C). Furthermore, three landraces were selected, among them the lowest (CGN19821) and the highest (CGN19656) emitter of all accessions used in this study. For all selected accessions, the predatory mites significantly preferred volatiles induced by spider mites or jasmonic acid to blends of non-induced plants (data not shown). Accessions CGN23412, Hybrid C, and Hybrid $\mathrm{T}$ were infested with 50 spider mites on each plant and tested against each other $7 \mathrm{~d}$ after the onset of infestation. Preferences of predatory mites could be ranked
Table 2 Total amount of volatiles [least-squares means ng plant \pm SE], i.e. the sum of 24 compounds emitted by 3 -wk-old plants of 15 cucumber accessions in response to $( \pm)-\mathrm{JA}$ $(0.5 \mathrm{mM})$ spraying

EU-1, F1 hybrid developed by PRI formerly CPRO-DLO, The Netherlands

EU-2, F1 hybrid developed by Dutch Seed company

EU-3, F1 hybrid developed by Seminis, India

EU-4, F1 hybrid developed by Nunhems, The Netherlands

JP-1, Japanese F1 hybrid

\begin{tabular}{|c|c|c|c|c|c|}
\hline \multirow[t]{3}{*}{ Accession } & \multirow[t]{3}{*}{ Country of origin } & \multicolumn{4}{|c|}{ Total amount $[\mathrm{ng} \pm \mathrm{SE}]$ of volatiles emitted } \\
\hline & & \multirow[t]{2}{*}{ Control plants } & \multicolumn{2}{|c|}{ JA treated plants } & \multirow[t]{2}{*}{$N$} \\
\hline & & & $2 d$ & $3 d$ & \\
\hline CGN19821 & Nepal & $4.2 \pm 2.2$ & $93.6 \pm 9.8$ & $78.2 \pm 7.6$ & 5 \\
\hline CPRO1 & EU-1 & $9.5 \pm 2.5$ & $127.7 \pm 19.2$ & $364.2 \pm 25.3$ & 5 \\
\hline Hybrid $\mathrm{T}$ & EU-2 & $14.3 \pm 3.6$ & $168.0 \pm 33.5$ & $334.2 \pm 51.7$ & 5 \\
\hline $\mathrm{CPRO} 2$ & EU-1 & $13.5 \pm 4.8$ & $263.4 \pm 31.9$ & $420.1 \pm 63.1$ & 5 \\
\hline CGN23412 & Egypt & $23.7 \pm 5.6$ & $349.7 \pm 31.4$ & $614.5 \pm 67.5$ & 5 \\
\hline CGN22310 & Kazachstan & $11.7 \pm 7.6$ & $354.2 \pm 54.0$ & $234.5 \pm 35.7$ & 5 \\
\hline Dasher II & EU-3 & $19.7 \pm 2.5$ & $393.4 \pm 37.9$ & $889.5 \pm 61.7$ & 5 \\
\hline Korinda & EU-4 & $6.9 \pm 1.8$ & $480.9 \pm 64.8$ & $753.6 \pm 98.3$ & 5 \\
\hline Sharp1 & JP-1 & $12.3 \pm 7.3$ & $616.7 \pm 80.1$ & $648.5 \pm 100.2$ & 5 \\
\hline Hybrid C & EU-2 & $17.6 \pm 2.6$ & $836.3 \pm 59.4$ & $807.4 \pm 100.3$ & 12 \\
\hline CGN21623 & Libanon & $39.0 \pm 9.4$ & $952.1 \pm 74.6$ & $2,090.4 \pm 232.7$ & 5 \\
\hline Vetabit & unkown & $22.7 \pm 3.8$ & $1,086.9 \pm 131.4$ & $4,449.4 \pm 395.6$ & 5 \\
\hline CGN20890 & India & $14.6 \pm 2.6$ & $1,095.1 \pm 171.6$ & $3,526.0 \pm 387.2$ & 5 \\
\hline CGN19568 & Pakistan & $29.5 \pm 4.2$ & $1,740.9 \pm 168.0$ & $2,451.2 \pm 368.3$ & 5 \\
\hline CGN19656 & Iran & $12.8 \pm 6.8$ & $2,642.4 \pm 355.2$ & $6,051.4 \pm 573.7$ & 5 \\
\hline
\end{tabular}


Fig. 2 Relative contribution of individual volatile compounds to the total volatile blend of different Cucumis sativus accessions $2 \mathrm{~d}$ after treatment with JA ( $0.5 \mathrm{mM} ; 15$ accessions) or after $7 \mathrm{~d}$ of spider-mite infestation (Sp, seven accessions)

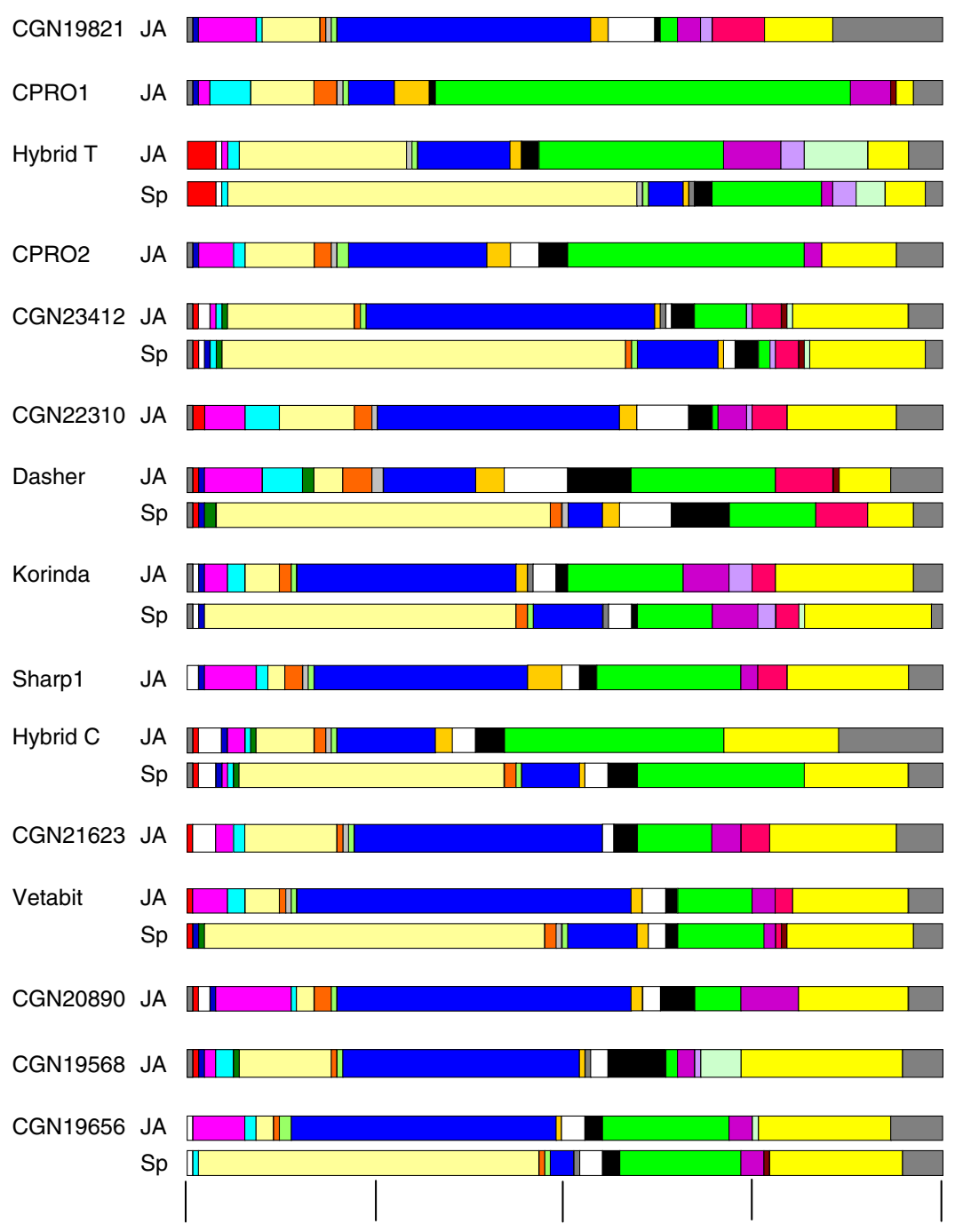

Relative contribution of the total volatile blend from CGN23412 > Hybrid C $>$ Hybrid $\mathrm{T}(P<0.01$; Fig. 5). Although Hybrid $\mathrm{C}$ had the highest total release of volatiles (Fig. 1), this did not result in the strongest attraction of predatory mites. The individual volatiles of the miteinfested plants could be ranked according to their attractiveness to predatory mites. This ranking was correlated positively with the relative amounts of $(E)$-2-hexenal, $(E)$ $\beta$-ocimene, $(E)-\beta$-caryophyllene, and $(E, E)-\alpha$-farnesene in the volatile blend (Fig. 5b).
In a parallel experiment, a selection of accessions were treated with JA and used in the Y-tube olfactometer at different times after the onset of the treatment (Fig. 6). Predatory mites preferred the volatiles released by JAtreated CGN19656 above those of Hybrid C, Hybrid T, or CGN19821. The preference was maximal 2-3 d after JA application and diminished afterwards (Fig. 6). As CGN19656 was by far the highest emitter of volatiles (Table 1), this preference is correlated strongly with the 


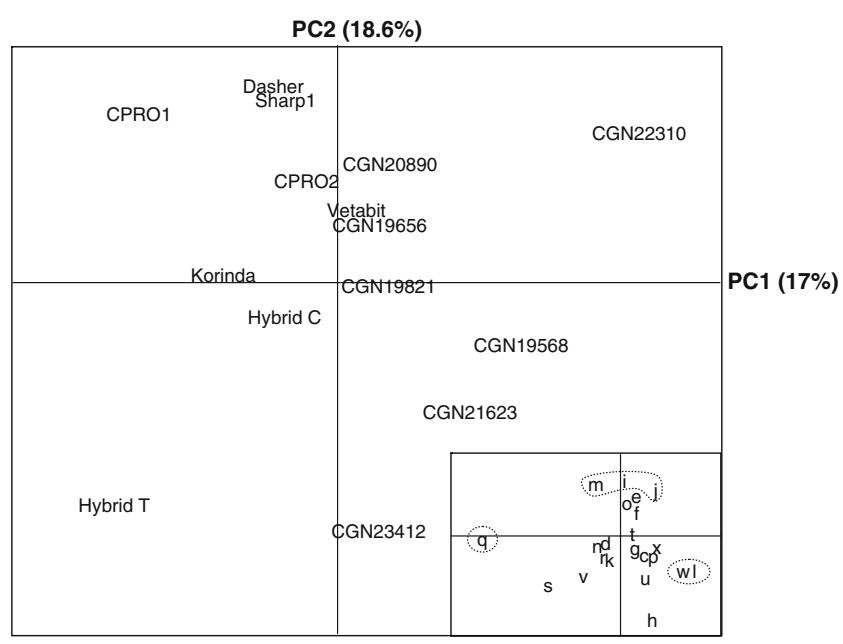

Fig. 3 Principal component analysis based on Pearson's correlations: the second principal component PC2 versus the third principal component PC3 of JA-induced volatiles in cucumber. Inset shows the loading plot, letters indicate individual volatile compounds, as explained in Table 2. Dotted circles indicate those volatiles that are discussed in the text absolute amount of induced volatiles. Therefore, it is valuable to study the difference between e.g., Hybrid $\mathrm{T}$ and CGN19821, that both emit low amounts of volatiles (Table 2). In this case, volatiles released by CGN19821 were significantly more attractive to predatory mites 2 and 3 d after JA application (Fig. 6). CGN19821 had significantly higher proportions of 3-methyl-butanal- $O$ methyloxime, $(E)-\beta$-ocimene, and $(E)-\beta$-caryophyllene in its blend, whereas the blend of Hybrid $\mathrm{T}$ was relatively rich in (Z)-3-hexenyl acetate and DMNT (Fig. 2). The blend of Hybrid $\mathrm{C}$ also was more attractive than that of Hybrid $\mathrm{T}$ on day 3 (Fig. 6). Hybrid $\mathrm{C}$ is relatively rich in $(E, E)-\alpha-$ farnesene and TMTT, and low in (Z)-3-hexenyl acetate as compared to the blend of Hybrid T (Fig. 2).

\section{Discussion}

Varietal or genotypic differences in herbivore-induced plant volatiles have been studied primarily in cultivars of agricultural crops, including cotton (Loughrin et al. 1995),
Fig. 4 Volatile-volatile correlation matrix of the $24 \mathrm{com}$ pounds emitted by JA-treated cucumber plants. Correlations between volatiles are shown in gray scale: the darker the gray color, the higher the percentage of similarity between metabolite expression patterns. Lined boxes show those clusters that are discussed in the text unknown sesquiterpenoid 3 methyl salicylate

(Z)-3-hexen-1-yl acetate unknown sesquiterpenoid 2 DMNT 1-hexanol nonanal nitrile

(E)- $\beta$-caryophyllene 3-Me-butanal-O-Me-oxime thujene $\alpha$-phellandrene limonene

(Z)-3-hexen-1-yl-butyrate decanal unknown sesquiterpenoid 1

(E)- $\beta$-ocimene $(E, E)$ - $\alpha$-farnesene (E,E)-TMTT oxime 1 linalool (Z)- $\beta$-ocimene

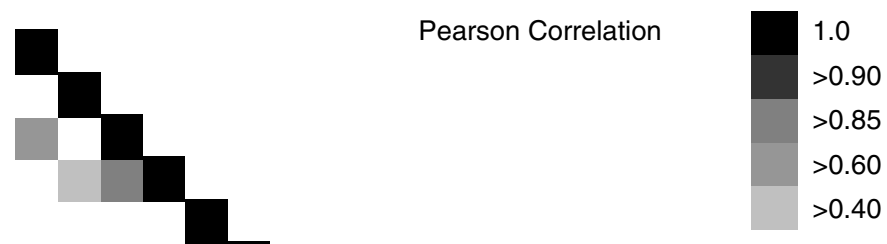

$>0.90$ $>0.85$<smiles>C1CC1</smiles>
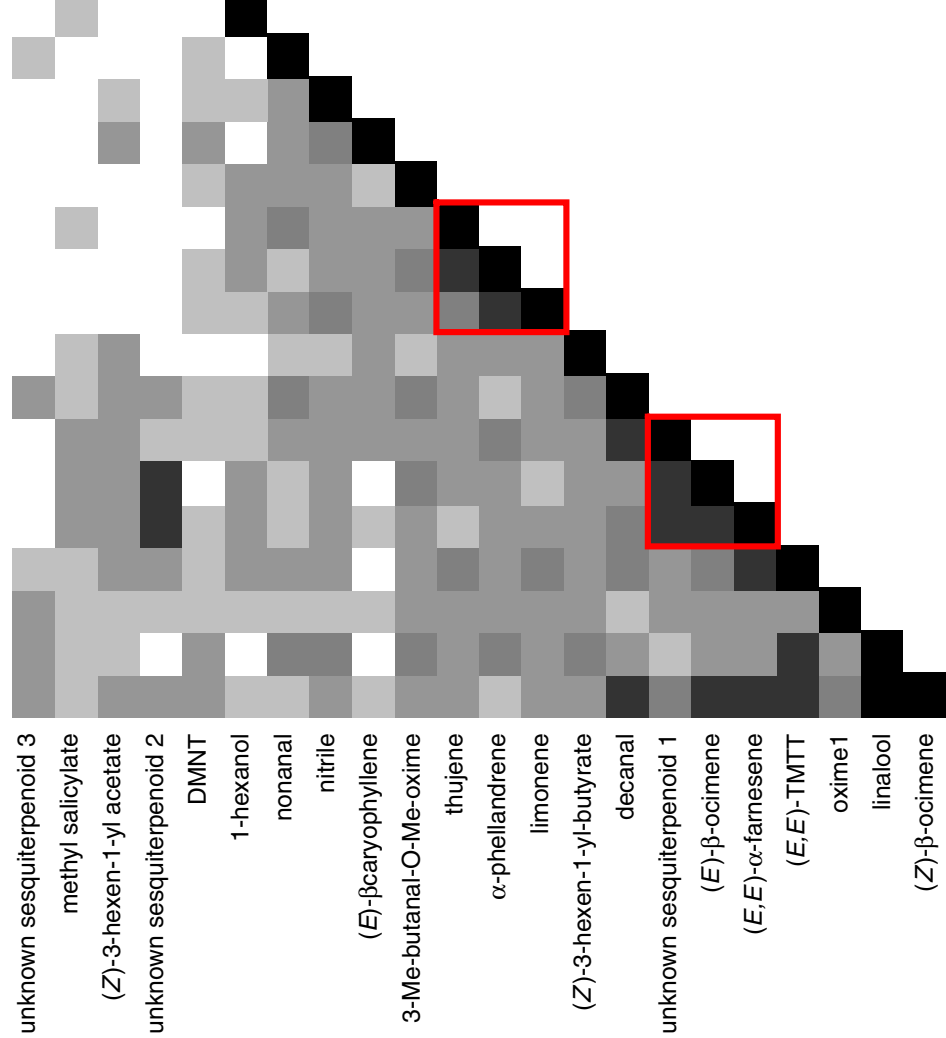
Fig. 5 Relative preference of Phytoseiulus persimilis for headspace from three different Cucumis sativus accessions infested with Tetranychus urticae for $7 \mathrm{~d}$. a $\%$ of predatory mites to each odor source, asterisks indicate level of significance, as tested with a twosided binomial test: $n s$, not significant, $* P<0.05, * * P<$ $0.01, * * * P<0.001$; and $\%$ of predatory mites that did not make a choice within the given time period. b Relative contribution to the total blend (means \pm SE) of $(E)$-2-hexenal (grey bars), (E)- $\beta$-ocimene (dashed bars), (E)- $\beta$-caryophyllene (white bars), and (E,E)- $\alpha$-farnesene (black bars) in accessions Hybrid C, Hybrid T and CGN23412
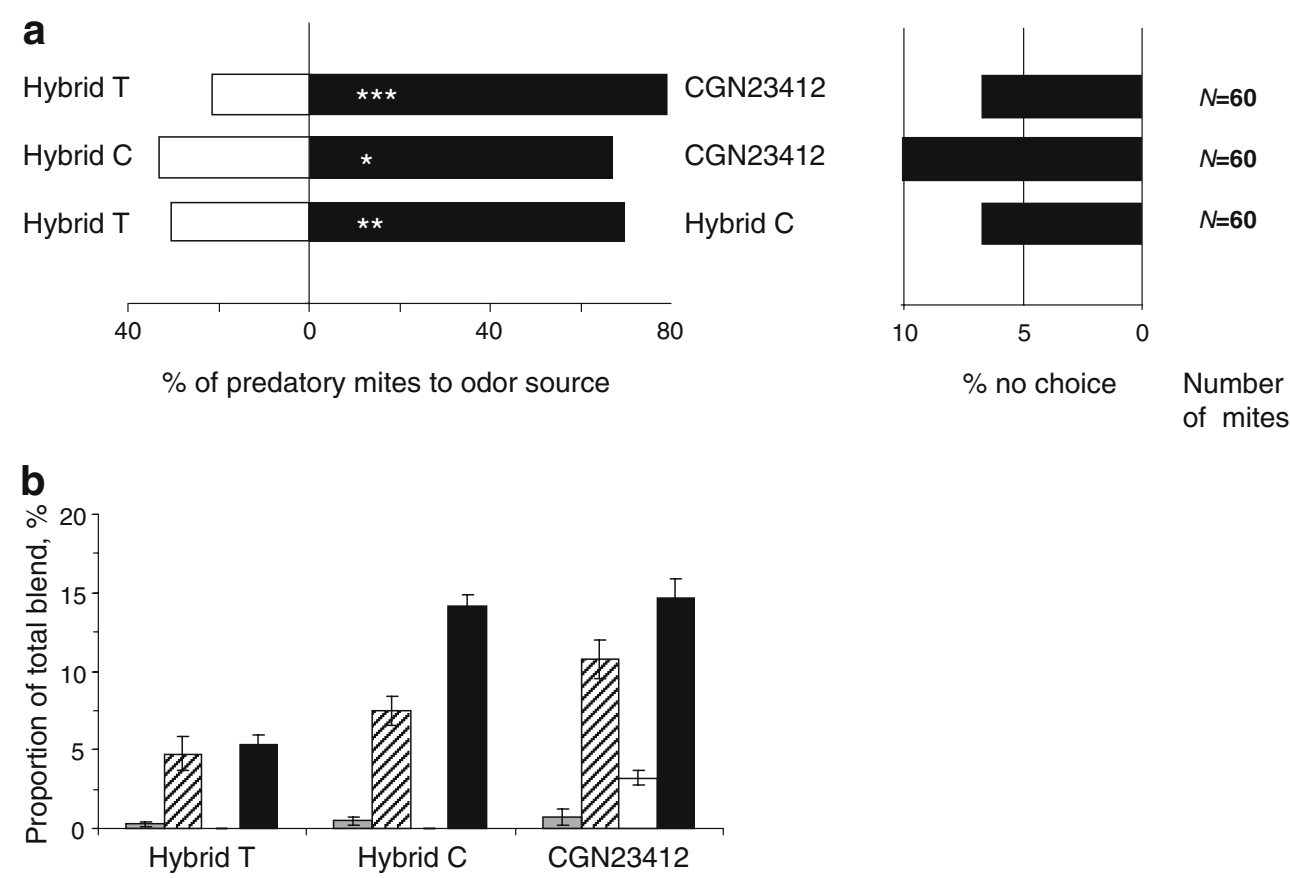

gerbera (Krips et al. 2001), pear (Scutareanu et al. 2003), maize (Hoballah et al. 2004), carrot (Nissinen et al. 2005), rice (Lou et al. 2006), and cruciferous crops (Bukovinszky et al. 2005). In a study that used 31 maize hybrid lines, for example, about 70 -fold variation in the quantity of volatiles emitted was found (Degen et al. 2004). The significance of such variation in volatile production among different accessions with respect to the attraction of natural enemies can be evaluated only by behavioral bioassays. For some natural enemies, differential attraction to the odors of

Fig. 6 Relative preferences of Phytoseiulus persimilis for headspace of three different Cucumis sativus accessions sprayed with $0.5 \mathrm{mM}$ jasmonic acid. Bioassays were conducted three times during $4 \mathrm{~d}$ following JA treatment (day 1, 2, 3, 4 since JA treatment, as indicated in the bars). Asterisks indicate level of significance, as tested with a two-sided binomial test: $n s$, not significant, $* P<0.05$, $* * P<0.01, * * * P<0.001$.

Numbers of mites are those mites that made a choice for one of either odor sources

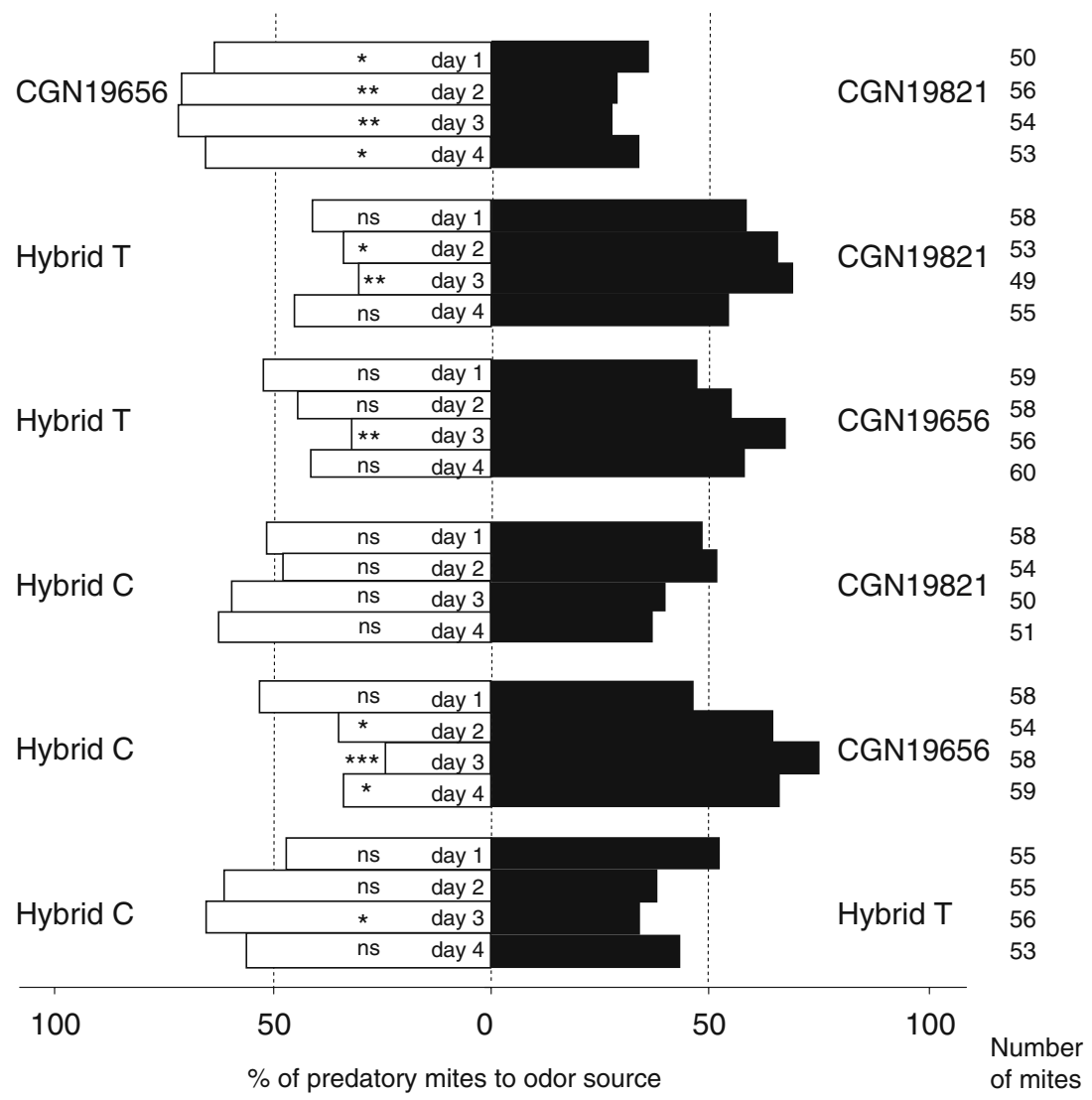


particular accessions has been demonstrated (Krips et al. 2001; Hoballah et al. 2002; Bukovinszky et al. 2005). Here, we showed that differences in induced volatile profiles also exist among cucumber accessions and have consequences for predator attraction.

Uninduced cucumber plants released less than $3 \%$ of the volatiles emitted by induced plants with $(E)$-2-hexenal and (Z)-3-hexenyl acetate as predominant compounds (Table 2). There were no pronounced differences in the composition of the volatiles collected from undamaged leaves of the European F1-hybrids and landraces from Asia and Africa. The release of these compounds is caused probably by minor damage due to handling of the plants.

The release of induced volatiles varied from $80 \mathrm{ng}$ to over $6 \mu \mathrm{g}$ per plant after JA application. Tetranychus urticae infestation did not cause a similar increase in volatile production, likely because feeding damage is progressing relatively slowly with the development of the mite population, and the plant can adapt to the changing situation, whereas JA application quickly activates the whole signalling cascade to a maximum within 2-3 d. JA application was used to standardize the level of induction and, therefore, is a more accurate induction treatment to investigate potential differences in induced volatile production among various accessions.

A total of 24 compounds, representing approximately $98 \%$ of the trapped volatiles, were identified. The majority of the volatile blend consisted of terpene hydrocarbons, with the most abundant components being the monoterpene $(E)-\beta$-ocimene and the homoterpene (E)-4,8-dimethyl-1,3,7-nonatriene (DMNT) Also, the sesquiterpene $(E, E)$ - $\alpha$-farnesene and another homoterpene (E,E)-4,8,12-trimethyl-1,3,7,11-tridecatetraene (TMTT) were among the most abundant volatiles in the released blend. The homoterpenes DMNT and TMTT result from oxidative degradation of the sesquiterpenoid nerolidol and the diterpenoid geranyllinalool, respectively (Gäbler et al. 1991). Although both nerolidol and geranyllinalool are volatile, we detected only nerolidol occasionally in the volatile blend of some of the accessions used, indicating an efficient conversion of the alcohols into the homoterpenes. In other species, like e.g., maize and rice, nerolidol has been found in the herbivory-induced blend, but always together with the degradation product DMNT (Degen et al. 2004; Lou et al. 2006). Besides nerolidol, the only other terpene alcohol detected was linalool, which was found in six accessions. In induced volatile blends of many plant species, linalool is the only terpene alcohol, although in Norway spruce $\alpha$-terpineol, camphenilol, and borneol also were found (Martin et al. 2003).

Compared to previous studies (Dicke et al. 1990a; Bouwmeester et al. 1999; Mercke et al. 2004), we detected a number of new herbivory-induced volatiles: 2-hexanal, linalool, methyl salicylate, $\beta$-caryophyllene, $\alpha$-phellandrene, thujene, and three unknown sesquiterpenoids in some of the accessions. These differences may be due to treatment differences. Herbivore- or elicitor-induced volatile release varies with time and treatment, applied amount of elicitor (Halitschke et al. 2000), and the herbivore damage level (Gouinguene et al. 2003). In our study, spider-mite infestation and JA treatment led to qualitative as well as quantitative differences in the volatile profile (Fig. 2). The volatile components released by the accessions used due to spider-mite infestation also were detected in the blend of JAtreated plants, although in most of the accessions JAtreatment led to the emission of a larger number of compounds than were emitted in response to spider-mite feeding (Fig. 2). Exceptions are (Z)-3-hexen-1-yl butyrate and an unknown sequiterpenoid, which were found in the headspace of spider-mite infested plants of accessions Dasher and Korinda, respectively, but not in the blends of JA-treated plants of these accessions. Apparently, spider mites are not capable of triggering the whole induced volatile potential that cucumber plants have, and JA application resulted in a more 'JA-specific volatile response' that does not mimic exactly the herbivore-induced volatile blend. Herbivore damage likely influences alternative defense pathways that control volatile emission (De Boer and Dicke 2004). Herbivores with piercing-sucking mouthparts may induce more salicylic acid (SA)-mediated defense genes compared to chewing herbivores (Leitner et al. 2005; Zhang et al. 2009). The SA and JA signal-transduction pathways may interact (Pieterse et al. 2009) and lead to different induced volatiles blends

By using PCA based on Pearson correlations on least square means of absolute amounts, the accessions investigated were separated principally on the basis of total volatile emission. Therefore, we focused on the proportions of the compounds in the blend, as this may lead to a better distinction between accessions. The accessions used are not genetically characterized, but quite randomly selected. Nonetheless, our PCA data show a clear difference between European F1-hybrids and the landraces from Asia and Africa, mostly distinguished by the proportions of DMNT, $(E)$ - $\beta$-ocimene, and $(E, E)-\alpha$-farnesene in the odor blend (Fig. 3). Our results show that, at least for this limited selection of accessions, the European F1 hybrids have lost the capacity to produce large amounts of $(E)$ - $\beta$-ocimene and $(E, E)-\alpha$-farnesene. As a 'chemical signature' is determined by relative amounts, the consequence is that the induced blends of European hybrids are characterized by a relatively higher proportion of DMNT.

Several compounds identified in cucumber volatile blends could be clustered by using a Pearson correlation matrix. With the exception of $(E)-\beta$-ocimene, the principal volatile emitted in ten accessions, the emission rates of the 
non-alcohol monoterpenes, limonene, $\alpha$-phellandrene, and thujene were mutually correlated, suggesting that these three monoterpenes may be formed by a single enzyme that is induced upon herbivory. Indeed, several multiproduct synthases have been cloned, e.g., from maize (Köllner et al. 2004), Arabidopsis (Tholl et al. 2005), and Medicago truncatula (Arimura et al. 2008). Multi-product terpene synthases significantly contribute to the plasticity of blends and are increasingly found in plants, especially in the context of herbivory (Köllner et al. 2004; Tholl et al. 2005; Arimura et al. 2008). Interestingly, the monoterpene (E)- $\beta$ ocimene does not correlate with the other monoterpenes, but it is correlated positively with the sesquiterpene $(E, E)$ $\alpha$-farnesene, and another unknown sesquiterpene (Pearson coefficient $=0.97$ ). This matches well with previously published data that show that the $(E, E)$ - $\alpha$-farnesene synthase cloned from spider mite-induced cucumber plants also catalyzes the formation of $(E)$ - $\beta$-ocimene from geranyl diphosphate (Mercke et al. 2004). Furthermore, the (E,E)$\alpha$-farnesene synthase also produced sesquiterpene in enzymatic assays with a similar RI as 'unknown sesquiterpenoid one' detected in this study. This gene possesses a plastid targeting peptide and hence is likely to produce $(E)-\beta$ ocimene when activated/induced by herbivory. Indeed, in time course studies, $(E)$ - $\beta$-ocimene is among the first volatiles released by cucumber (Bouwmeester et al. 1999; Mercke et al. 2004). When herbivory progresses, other volatile compounds are released, amongst them $(E, E)-\alpha-$ farnesene. These results suggest then farnesyl diphosphate becomes available in the plastids. To date, increasing evidence is accumulating that the plastidial MEP pathway also may significantly contribute to cytosolic sesquiterpene biosynthesis by allowing IPP to be shuttled between cell compartments (Bick and Lange 2003). Aharoni et al. (2003) suggest that FPP is available in the plastids, based on the observation that transgenic Arabidopsis plants harboring a heterologous sesquiterpene synthase from strawberry emit low amounts of the sesquiterpene $(E)$-nerolidol. The exact mechanism remains to be elucidated.

Jasmonic-acid-induced volatiles of accessions CGN19656 and CGN19821 were significantly preferred by $P$. persimilis predatory mites over those of Hybrid $\mathrm{T}$ and Hybrid C. As CGN19656 is by far the highest emitter of volatiles, it is not unexpected that this landrace is highly attractive. In contrast, CGN19821 is a landrace that releases low amounts of volatiles, but its blend attracts more predators than the JAinduced blend of Hybrid $\mathrm{T}$, and is equally attractive to the blend of Hybrid C, both of which had an almost 2-fold (Hybrid T) to 9-fold (Hybrid C) higher release of volatiles (Table 1). The relative contributions of 3-methyl-butanal- $O$ methyloxime, $\beta$-caryophyllene, and $(E)$ - $\beta$-ocimene to the 'chemical signature' of the induced blend were significantly higher in CGN19821 than in Hybrid C and Hybrid T
(Fig. 2), and this could correlate with its higher degree of predator attraction. In contrast, the proportions of the green leaf volatiles (Z)-3-hexen-1-ol, 1-hexanol, and (Z)-3-hexen1-yl butyrate were lower in CGN19821 than in the other two accessions.

Preferences of predatory mites also were studied after spider-mite infestation in cucumber accessions CGN23412, Hybrid T, and Hybrid C. The ranking order of attractiveness in accessions infested with spider mites correlated with the relative proportion of $(E)$-2-hexenal, $(E)$ - $\beta$-ocimene, $(E)-\beta$ caryophellene, and $(E, E)-\alpha$-farnesene. Similarly, Loughrin et al. (1995) found that differences in volatile production of cotton cultivars were based mainly on differences in the production of terpenes. Moreover, Krips et al. (2001) concluded that the lower attractiveness of $P$. persimilis to certain gerbera cultivars correlated with the relatively lower emission rates of $(E)$ - $\beta$-ocimene and linalool in the total volatile blend of these less attractive cultivars. Our study indicates that in cucumber $(E)$ - $\beta$-ocimene and $(E)-\beta$ caryophyllene play an important role in the attraction of predatory mites. Previously, it has been shown that $P$. persimilis and other predatory mites are attracted to linalool, methyl salicylate, $(E)-\beta$-ocimene, DMNT, and $(E)$-nerolidol, when offered individually (Dicke et al. 1990b; De Boer et al. 2004; Kappers et al. 2005). From our data, it seems that the proportion of DMNT within the total blend is not very important for the attraction of $P$. persimilis to induced cucumber volatiles: accessions Hybrid $\mathrm{T}$ and Hybrid $\mathrm{C}$, both with relatively high proportions of DMNT, were less attractive in comparison to CGN19656 and CGN19821. However, transgenic Arabidopsis plants expressing a nerolidol synthase gene from strawberry (Kappers et al. 2005) emit more DMNT and were significantly more attractive to predatory mites. Additionally, Mumm et al. (2008) found less attraction of parasitoid wasps Diadegma semiclausum when Arabidopsis plants were treated with fosmidomycin, which specifically inhibits 1-deoxy-d-xylulose 5-phosphate reductoisomerase (DXPR), a key enzyme in the methylerythritol 4-phosphate (MEP) pathway, located in the plastids. However, other terpenoid compounds also were reduced in this study, which limits the conclusion concerning DMNT. Another example of an individual compound that affects the attraction of natural enemies is $(E)$ - $\alpha$-bergamotene that increased Manduca sexta egg predation rates on Nicotiana attenuata by the generalist predator Geocoris pallens (Kessler and Baldwin 2001). Most of these studies used single compounds or mixtures, ignoring the fact that background odors of plants may have a large impact on the 'chemical signature' (Schroeder and Hilker 2008).

The relative production of (Z)-3-hexen-1-yl-acetate was higher in Hybrid $\mathrm{T}$ than in other accessions. (Z)-3-Hexen1 -yl-acetate was found to be neither attractive nor 
repellent for P. persimilis (Dicke et al. 1990b). Van Wijk et al. (2008) also did not find a response of predatory mites towards this compound. Takabayashi et al. (1994) found indications that two oximes might be repellent to $P$. persimilis. In our study, the relatively high proportion of 3-methyl-butanal- $O$-methyloxime in accession CGN19821 was not found to prevent predatory mites from choosing this accession when tested against accessions with lower production of oxime. Interestingly, 3-methyl-butanal- $O$ methyloxime has been reported to be induced by Pythium aphanidermatum infestation of cucumber plants as well (Jansen et al. 2007), thus suggesting a common defense signalling pathway for these two different types of biotic stress.

In summary, this study demonstrates a large range of quantitative as well as qualitative variation for herbivory induced volatile emission by different cucumber accessions. Behavioral studies with predatory mites $P$. persimilis show that these differences have a profound effect on the attraction of a natural enemy of spider mites. We currently are addressing the effects of differentially attractive accessions on predatory mites under greenhouse conditions to exploit the genetic variation for the realization of sustainable horticulture with a reduced use of pesticides.

\begin{abstract}
Acknowledgements The authors thank Leo Koopman for rearing of insects, ENZA Zaden, Enkhuizen, The Netherlands, another anonymous Dutch Seeds company, and the Centre for Genetic Resources The Netherlands (CGN), Wageningen, The Netherlands for cucumber seeds. We thank four anonymous reviewers for their insightful comments on a previous version of the manuscript. The Netherlands Organization for Scientific Research (NWO) is acknowledged for a Technology Foundation grant STW 5479 to I.F.K. and L.L.P.L and a VICI grant 865.03.002 to M.D.
\end{abstract}

Open Access This article is distributed under the terms of the Creative Commons Attribution Noncommercial License which permits any noncommercial use, distribution, and reproduction in any medium, provided the original author(s) and source are credited.

\section{References}

ADAMS, R. P. 1995. Identification of Essential Oil Components by Gas Chromatography/Mass Spectrometry. Allured Publishing Corp., Carol Stream.

Agrawal, A. A. 2001. Phenotypic plasticity in the interactions and evolution of species. Science 294:321-326.

Aharoni, A., Giri, A.P., Deuerlein, S., Griepink, F., De Kogel, W. J., Verstappen, F. W. A., Verhoeven, H. A., Jongsma, M. A., Schwab, W., and BouwmeEster, H. J. 2003. Terpenoid metabolism in wild-type and transgenic Arabidopsis plants. Plant Cell 15:2866-2884.

Aharoni, A., Jongsma, M. A., and Bouwmeester, H. J. 2005. Volatile science? Metabolic engineering of terpenoids in plants. Trends Plant Sci. 10:594-602.

Arimura, G., Kost, C., and Boland, W. 2005. Herbivore-induced, indirect plant defences. Biochim. Biophys. Acta 1734:91-111.
Arimura, G.-I., Garms, S., Maffei, M., Bossi, S., Mithöfer, A., Schulze, B., Leitner, M., and Boland, W. 2008. Herbivoreinduced terpenoid emission in Medicago truncatula: concerted action of jasmonate, ethylene and calcium signaling. Planta 227:453-464.

Balkema-Boomstra, A. G., Zijlstra, S., Verstappen, F. W. A., IngGamer, H., Mercke, P. E., Jongsma, M. A., and BouwMEESTER, H. J. 2003. Role of cucurbitacin C in resistance to spider mite (Tetranychus urticae) in cucumber (Cucumis sativus L.). J. Chem. Ecol. 29:225-235.

BICK, J. A., and LANGe, B. M. 2003. Metabolic cross talk between cytosolic and plastidial pathways of isoprenoid biosynthesis: unidirectional transport of intermediates across the chloroplast envelope membrane. Arch. Biochem. Biophys. 415:146-154.

Bouwmeester, H. J., Verstappen, F. W. A., Posthumus, M. A., and DiCKE, M. 1999. Spider mite-induced (3S)-(E)-nerolidol synthase activity in cucumber and lima bean. The first dedicated step in acyclic C11-homoterpene biosynthesis. Plant Physiol. 121:173-180.

Bukovinszky, T., Gols, R., Posthumus, M. A., Vet, L. E. M., and VAN LENTEREN, J. C. 2005. Variation in plant volatiles and attraction of the parasitoid Diadegma semiclausum (Hellen). J. Chem. Ecol. 31:461-480.

D'Alessandro, M., and Turlings, T. C. J. 2006. Advances and challenges in the identification of volatiles that mediate interactions among plants and arthropods. Analyst 131:24-32.

D'Auria, J. C., Pichersky, E., Schaub, A., Hansel, A., and GERSHENZON, J. 2007. Characterization of a BAHD acyltransferase responsible for producing the green leaf volatile (Z)-3-hexen1-yl acetate in Arabidopsis thaliana. Plant J. 49:194-207.

DE BOER, J. G., and DiCKE, M. 2004. The role of methyl salicylate in prey searching behavior of the predatory mite Phytoseiulus persimilis. J. Chem. Ecol. 30:255-271.

De Boer, J. G., Posthumus, M. A., and Dicke, M. 2004. Identification of volatiles that are used in discrimination between plants infested with prey or non-prey herbivores by a predatory mite. J. Chem. Ecol. 30:2215-2230.

Degen, T., Dillmann, C., Marion-Poll, F., and Turlings, T. 2004. High genetic variability of herbivore-induced volatile emission within a broad range of maize inbred lines. Plant Physio. 135: $1928-1938$

DegenhardT, D. C., and LinColn, D. E. 2006. Volatile emissions from an odorous plant in response to herbivory and methyl jasmonate exposure. J. Chem. Ecol. 32:725-743.

DiCKE, M. 1999. Direct and indirect effects of plants on beneficial organisms, pp. 105-153, in J. R. Ruberson (ed.). Handbook of Pest Management. Marcel Dekker, Inc, New York.

Dicke, M., and VAN LOON, J. J. A. 2000. Multitrophic effects of herbivore-induced plant volatiles in an evolutionary context. Ent. Exp. Appl. 97:237-249.

Dicke, M., Sabelis, M. W., Takabayashi, J., Bruin, J., and Posthumus, M. A. 1990a. Plant strategies of manipulating predator-prey interactions through allelochemicals-prospects for application in pest-control. J. Chem. Ecol. 16:3091-3118.

Dicke, M., VAN DER MaAs, K. J., TAKabayashi, J., and Vet, L. E. M. 1990b. Learning affects response to volatile allelochemicals by predatory mites. Exp. Appl. Entomol. 1:31-36.

Dicke, M., Gols, R., Ludeking, D., and Posthumus, M. A. 1999. Jasmonic acid and herbivory differentially induce carnivoreattracting plant volatiles in lima bean plants. J. Chem. Ecol. 25:1907-1922.

Dudareva, N., Negre, F., Nagegowda, D. A., and Orlova, I. 2006. Plant volatiles: recent advances and future perspectives. Crit. Rev. Plant Sci. 25:417-440.

GäBler, A., Boland, W., Preiss, U., and Simon, H. 1991. Stereochemical studies on homoterpene biosynthesis in higher- 
plants - mechanistic, phylogenetic, and ecological aspects. Helv. Chim. Acta 74:1773-1789.

Gols, R., Posthumus, M. A., and Dicke, M. 1999. Jasmonic acid induces the production of gerbera volatiles that attract the biological control agent Phytoseiulus persimilis. Ent. Exp. Appl. 93:77-86.

Gouinguene, S., Alborn, H., and Turlings, T. C. J. 2003. Induction of volatile emissions in maize by different larval instars of Spodoptera littoralis. J. Chem. Ecol. 29:145-162.

HalitschKe, R., Kessler, A., KaHL, J., LORENZ A., and BALDWIN, I. T. 2000. Ecophysiological comparison of direct and indirect defenses in Nicotiana attenuata. Oecologia 124:408-417.

HEIL, M. 2008. Indirect defence via tritrophic interactions. New Phytol. 178:41-61.

HILKER, M., and MEINERs, T. 2010. How do plants "notice" attack by herbivorous arthropods? Biol. Rev. doi:10.1111/j.1469185X.2009.00100.x (in press).

Hoballah, M. E. F., Tamo, C., and Turlings, T. C. J. 2002. Differential attractiveness of induced odors emitted by eight maize varieties for the parasitoid Cotesia marginiventris: is quality or quantity important? J. Chem. Ecol. 28:951-968.

Hoballah, M. E., Kollner, T. G., Degenhardt, J., and Turlings, T. C. J. 2004. Costs of induced volatile production in maize. Oikos 105:168-180.

Huang, S., Li, R., Zhang, Z., Li, L., Gu, X., et al. 2009. The genome of the cucumber, Cucumis sativus L. Nat. G. 41:1275-1281.

Jansen, R. M. C., Postma, J., Verstappen, F. W. A., BouWMeEster, H. J., Posthumus, M. A., and Van Henten, E. J. 2007. Changes in volatile emission of cucumber plants after inoculation with the root pathogen Pythium aphanidermatum. Abstract book of the Joint International Workshop on PR proteins and induced resistance against pathogens and insects, 10-14 May 2007, Doorn, The Netherlands, p. 68.

KapPers, I. F., Aharoni, A., VAN Herpen, T. W. J. M., LuCKerhofF, L. L., Dicke, M., and Bouwmeester, H. J. 2005. Genetic engineering of terpenoid metabolism attracts bodyguards to Arabidopsis. Science 309:2070-2072.

KESSLER, A., and BALDWIN, I. T. 2001. Defensive function of herbivore-induced plant volatile emissions in nature. Science 291:2141-2144

Köllner, T. G., Schnee, C., Gershenzon, J., and Degenhardt, J. 2004. The sesquiterpene hydrocarbons of maize (Zea mays) form five groups with distinct developmental and organ-specific distribution. Phytochemistry 65:1895-1902.

Krips, O. E., Willems, P. E. L., Gols, R., Posthumus, M. A., GorT, G., and DiCKE, M. 2001. Comparison of cultivars of ornamental crop Gerbera jamesonii on production of spider mite-induced volatiles, and their attractiveness to the predator Phytoseiulus persimilis. J. Chem. Ecol. 27:1355-1372.

LeITNER, M., BOLAND, W., and MithÖFER, A. 2005. Direct and indirect defences induced by piercing-sucking and chewing herbivores in Medicago truncatula. New Phytol. 167:597-606.

Lou, Y.G., HuA, X. Y., Turlings, T. C. J., Cheng, J., Chen, X., and YE, G. 2006. Differences in induced volatile emissions among rice varieties result in differential attraction and parasitism of Nilaparvata lugens eggs by the parasitoid Anagrus nilaparvatae in the field. J. Chem. Ecol. 32:2375-2387.

Loughrin, J. H., Manukian, A., Heath, R. R., and Tumlinson, J. H. 1995. Volatiles emitted by different cotton varieties damaged by feeding beet armyworm larvae. J. Chem. Ecol. 21:1217-1227.

Martin, D. M., Gershenzon, J., and Bohlmann, J. 2003. Induction of volatile terpene biosynthesis and diurnal emission by methyl jasmonate in foliage of Norway spruce. Plant Physiol. 132:1586-1599.

Mercke, P., Kappers, I. F., Verstappen, F. W. A., Vorst, O. F. J., Dicke, M., and BouwMEeSTER, H. J. 2004. Combined transcript and metabolite analysis reveals genes involved in spider mite induced volatile formation in cucumber plants. Plant Physiol. 135:2012-2024.

MuMM, R., and HiLKER, M. 2006. Direct and indirect chemical defence of pine against folivorous insects. Trends Plant Sci. 11:351-358.

Mumm, R., Posthumus, M. A., and Dicke, M. 2008. Significance of terpenoids in induced indirect plant defence against herbivorous arthropods. Plant Cell Environ. 31:575-585.

Nissinen, A., Ibrahim, M., Kainulainen, P., TillikKala, K., and Holopainen, J. 2005. Influence of carrot psyllid (Trioza apicalis) feeding or exogenous limonene or methyl jasmonate treatment on composition of carrot (Daucus carota) leaf essential oil and headspace volatiles. J. Agric. Food Chem. 53:8631-8638.

OZAWA, R., ShiojiRI, K., SABElis, M. W., and TAKABAYASHI, J. 2008. Maize plants sprayed with either jasmonic acid or its precursor, methyl linolenate, attract armyworm parasitoids, but the composition of attractants differs. Ent. Exp. Appl. 129:189-199.

Pieterse, C. M. J., Leon-Reyes, A., VAN DER ENT, S., and VAN WeES, S. C. M. 2009. Networking by small-molecule hormones in plant immunity. Nature Chem. Biol. 5:308-316.

RODRÍGUEZ-CONCEPCIÓN, M. 2006. Early steps in isoprenoid biosynthesis: multilevel regulation of the supply of common precursors in plant cells. Phytochem. Rev. 5:1-15.

SCHROEDER, R., and HILKER, M. 2008. The relevance of background odor in resource location by insects: a behavioral approach. Bioscience 58:308-316.

Scutareanu, P., Bruin, J., Posthumus, M. A., and Drukker, B. 2003. Constitutive and herbivore-induced volatiles in pear, alder and hawthorn trees. Chemoecology 13:63-74.

StAuB, J. E., and MEGLIC, V. 1993. Molecular genetic markers and their relevance for cultivar discrimination: a case study in cucumber. HortTechnology 3:291-299.

STEPPUHN, A., and BALDwIN, I. T. 2008. Induced defenses and the cost-benefit paradigm, pp. 61-83, in A. Schaller (ed.). Induced Plant Resistance to Herbivory. Springer, Berlin.

TAKABAYASHI, J., and DiCKE, M. 1992. Response of predatory mites with different rearing histories to volatiles of uninfested plants. Ent. Exp. Appl. 1:109-113.

Takabayashi, J., Dicke, M., and Posthumus, M. A. 1994. Volatile herbivore-induced terpenoids in plant-mite interactions: variation caused by biotic and abiotic factors. J. Chem. Ecol. 20:1324-1354.

TATLIOGLU, T. 1993. Cucumber Cucumis sativus L., pp. 197-234, in G. Kalloo and B. O. Bergh (eds.). Genetic Improvement of Vegetable Crops. Pergamon Press Ltd., Tarrytown.

Tholl, D., Chen, F., Petri, J., Gershenzon, J., and Pichersky, E. 2005. Two sesquiterpene synthases are responsible for the complex mixture of sesquiterpenes emitted from Arabidopsis flowers. Plant J. 42:757-771.

Van den Boom, C. E. M., Van Beek, T. A., Posthumus, M. A., De Groot, A., and DICKE, M. 2004. Qualitative and quantitative variation among volatile profiles induced by Tetranychus urticae feeding on plants from various families. J. Chem. Ecol. 30:69-89.

Van Lenteren, J. C., and De Ponti, O. M. B. 1990. Plant-leaf morphology, host-plant resistance and biological control. Symp. Biol. Hung. 39:365-386.

VAN WiJK, M., DE Bruijn, P. J. A., and Sabelis, M. W. 2008. Predatory mite attraction to herbivore-induced plant odors is not a consequence of attraction to individual herbivore-induced plant volatiles. J. Chem. Ecol. 34:791-803.

Zhang, P. J., ZHENG, S. J., VAN LoON, J. J. A., BOland, W., DaVID, A., MumM, R., and Dicke, M. 2009. Whiteflies interfere with indirect plant defense against spider mites in Lima bean. Proc. Natl. Acad. Sci. USA 106:21202-21207. 